in an older population in the Netherlands: the Hoorn study. Am J Clin Nutr 2007;85:755-61.

14 Macfarlane GJ, Palmer B, Roy D, Afzal C, Silman AJ, O’Neill T. An excess of widespread pain among South Asians: are low levels of vitamin $D$ implicated? Ann Rheum Dis 2005;64:1217-9.

15 Allison TR, Symmons DPM, Brammah T, Haynes P, Rogers A, Roxby M, et al. Musculoskeletal pain is more generalised among people from ethnic minorities than among white people in Greater Manchester. Ann Rheum Dis 2002;61:151-6.

16 Plotnikoff GA, Quigley JM. Prevalence of severe hypovitaminosis D in patients with persistent, nonspecific musculoskeletal pain. Mayo Clin Proc 2003;78:1463-70.

17 Vieth R, Bischoff-Ferrari H, Boucher BJ, Dawson-Hughes B, Garland CF, Heaney RP, et al. The urgent need to recommend an intake of vitamin D that is effective. Am J Clin Nutr 2007;85:649-50.

18 Working group of the Australian and New Zealand Bone and Mineral Society, Endocrine Society of Australia and Osteoporosis Australia. Vitamin D and adult bone health in Australia and New Zealand: a position statement. Med J Aust 2005;182:281-5.

19 Lin J, Manson JE, Lee IM, Cook NR, Buring JE, Zhang SM. Intakes of calcium and vitamin D and breast cancer risk in women. Arch Intern Med 2007;167:1050-9.
20 Lappe JM, Travers-Gustafson D, Davies KM, Recker RR, Heaney RP. Vitamin D and calcium supplementation reduces cancer risk: results of a randomised trial. Am J Clin Nutr 2007;85:1586-91.

21 Autier P, Gandini S. Vitamin D supplementation and total mortality. A meta-analysis of randomized controlled trials. Arch Intern Med 2007;167:1730-7.

22 Bischoff-Ferrari HA, Giovannucci E, Willett WC, Dietrich T, Dawson-Hughes B. Estimation of optimal serum concentrations of 25 hydroxyvitamin D for multiple health outcomes. Am J Clin Nutr 2006;84:18-28.

23 Institute of Medicine of the National Academies. Dietary reference intakes: calcium, phosphorus, magnesium, vitamin D, and fluoride. Washington, DC: National Academy Press, 1997.

24 Holick MF. Sunlight and vitamin D for bone health and prevention of autoimmune diseases, cancers, and cardiovascular disease. Am /Clin Nutr 2004;80(suppl):1678-88S.

25 Health Protection Authority. Sunsense: protecting yourself from ultraviolet radiation. www.hpa.org.uk/radiation/understand/ information_sheets/sunsense_poster.htm

Accepted: 9 November 2007

\title{
A PATIENT'S JOURNEY Becoming a live kidney donor
}

\author{
Annabel Ferriman
}

FEATURE, $p$ 1342, ANALYSIS, p 1346, REVIEWS, pp 1377, 1378

\section{BMJ, London WC1H 9JR}

aferriman@bmj.com

BMJ 2008;336:1374-6 doi:10.1136/bmj.a277
This is one of a series of occasional articles by patients about their experience of traumatic medical events that offer lessons to doctors. The $B M$ J welcomes contributions to the series.

Please contact Peter Lapsley (plapsley@bmj.com) for guidance.
In 2007, Annabel Ferriman gave one of her kidneys to an old friend. This is the story of her journey through that process

Last year I gave one of my kidneys to an old friend, Ray, who was months away from needing dialysis because of polycystic kidney disease. The operation was a success. Ray is doing well and is back at work, and I feel completely healthy and have had no adverse effects.

It was a positive experience for both of us, but some aspects of the patient journey, in particular the endless tests leading up to the transplant, were so protracted that I was left seething with rage. I am recounting the tale partly to encourage other people to consider kidney donation, but also in the hope that hospitals might make the path for donors a little easier.

\section{A breezy first step}

I first offered my kidney to Ray at a party, after I had had a few drinks and was feeling expansive. Ray and his wife, Denise, had been telling me about Ray's kidney problems. He had been diagnosed with polycystic kidney disease about eight years earlier, and his kidney function was gradually deteriorating. His doctor had told him that he would ultimately need a kidney transplant. Denise would have donated one of hers, but she was not a good match, and their children were considered too young. Ray's only sister also had the disease.

I knew that I could manage perfectly well on one kidney and breezily offered him one of mine. $\mathrm{He}$ looked astonished at the idea and said very little. Later, I am afraid to say, I got cold feet. When I next saw Ray, I told him that my offer had been a joke and I had decided, if he didn't mind, to keep both my kidneys.

But then I began to think seriously about it and to discuss it with my husband and my two daughters, who are both in their 20s. Denise was a particularly old and valued friend. She and I had brought our children up together. My husband had been a junior doctor when our children were young, and during what felt like extremely long weekends when he was at the hospital for 72 hours at a stretch, I had taken my children round to Denise's house and spent many hours drinking tea while they played. She and Ray had provided what was almost a second home for them.

So when I discussed the idea with my family they were supportive, and I realised that it was not such a big step. I went back to Ray and told him that I was serious about the offer. I can remember his exact response: "I really don't know what to say."

\section{Tests and delays}

The next step was a trip to the Royal Free Hospital with Ray to be tested to see if I was a suitable donor. Rather to our astonishment, I turned out to be an excellent match.

There then began 16 months of tests, and it was during the last nine months of these that I became angry at what seemed to be unnecessary delays. I knew that I had to be thoroughly checked out for my own sake and the sake of the recipient, but I had naively thought that the hospital would be able to 


\section{A DOCTOR'S PERSPECTIVE}

Renal transplantation offers the best outcome for most patients with end stage renal failure, and this is reflected in national strategy and the 2006 Human Tissue Act. As the number of deceased donors has progressively fallen, the emphasis on living donors-who tend to be relatives or partners-has increased. Most transplant units have established clinical pathways for live related organ donation, which focus on ensuring that the donor completely understands the risks and benefits for informed consent, and confirming the donor's suitability as well as the recipient's health. Implementing these pathways has put pressure on existing infrastructure.

Annabel's generous offer to donate a kidney was a wonderful altruistic gift for both Raymond and society because it frees up a kidney from a deceased donor for someone else. However, donation carries an attendant risk of death ( $(0.01 \%)$, postoperative thromboembolic disease, wound pain, hypertension, and proteinuria. The recipient also risks loss of the transplant from surgical failure or through rejection, and the donor should be informed of this potential adverse outcome. The decision to donate is therefore an important one that needs to be reflected upon over time and not be rushed into.

Some units do not undertake pre-emptive living donor transplantation; many units leave a period of consideration for up to three months, and all units agree that it is inappropriate to rush through a live kidney donor work-up without giving the prospective donor a period for reflection.

Donor screening involves ensuring that the donation will not adversely affect the donor or the recipient. Unexpected abnormalities are often identified in the work-up process and require evaluation. This process provides effective screening for the donor, but it also ensures that the recipient is not exposed to exogenous malignancy, viral infection, or other risks. In Annabel's case, a new asymptomatic hepatic lesion was identified and managed through the appropriate multidisciplinary team process. Such lesions are usually benign, but not always. The time between identifying the abnormality and the team's conclusion was three months in Annabel's case, which is not satisfactory. However, the investigation of a donor has a lower priority than that for sick patients, although as the waiting lists for complex imaging have fallen rapidly in the past 12 months the waiting time has reduced substantially in our unit.

From the recipient's perspective, timing of transplantation is important and we plot the linear deterioration in renal function of the recipient to optimise this. The half life of a renal transplant is around 15 years, and that clock starts when the kidney is transplanted. Postponing the transplant as long as possible is advantageous but needs to be balanced by the health of the recipient and the availability of the donor. A prolonged time on dialysis should be avoided if possible. Unexpected changes in the recipient's renal function introduce extra uncertainty, which is a particular problem when the donor is working or has other fixed responsibilities.

The recipient's health needs to be assured when considering the resource implications of both cadaveric and live related renal transplantation. End stage renal failure is associated with a massively increased and progressive risk of cardiovascular disease, so potential transplant recipients need repeated work-up cycles. Normal tests often become abnormal over time, which leads to further and more detailed investigations, and this certainly caused a delay during Ray's work-up process.

Annabel's helpful account describes a process that we recognise was extended. Although this was considered unsatisfactory for the recipient, it was not without reason given the circumstances of the donor and the recipient. The process reflects early activation of the pathway, difficulties with managing intercurrent unexpected extrarenal abnormalities detected on screening, and a delay in adapting the pathway to the individual needs of a particular donor. Over the past 12 months, we have made substantial changes and investment in this increasingly important clinical pathway-for our last 10 living donor transplants, the average work-up time (from screening blood to operation) fell from 200 days to 116 days, and the proportion of living donated renal transplants in our unit rose from $20 \%$ to $30 \%$. It is anticipated that this will increase to around $50 \%$ over the next two years.

B S Fernando, Royal Free Hospital, London bimbi.fernando@royalfree.nhs.uk perform all the tests within a few months. Indeed, the kidney transplant nurse had told me with some pride that the transplant team had "protected" appointment slots, so that most of my tests could be performed on the same day.

Meanwhile, Ray's kidney function was falling steadily, from about 20\% when I first volunteered to $15 \%$ a year later. We had both been told that the result of the transplant would be better if it took place before he needed dialysis, so we were keen to get on with it. The transplant surgeons did not want to operate too early because transplanted organs have a finite life, so it is a waste to give someone a new kidney while he or she still has some function left in their own. But it felt to Ray and me as if they were leaving it rather late. We both thought he might unnecessarily have to go on dialysis.

Could the tests have been carried out more quickly? The marathon began with the consultant nephrologist taking a full history and examining me. (Unfortunately this had to be repeated six months later, because my notes went missing.) The tests then started. The first series consisted of the standard investigations for anyone planning to donate a kidney, and included an exercise electrocardiogram, a chest $x$ ray, an ultrasound of the bladder and kidneys, a dimercaptosuccinic acid (DMSA) scan, measurement of my glomerular filtration rate, and a computed tomography scan of the blood vessels to the kidney.

\section{An infuriating distraction}

Although some people like the idea of thorough checkups (indeed they pay private firms good money to carry them out), I am not one of them. I know enough about medicine to realise that any detailed search is bound to throw up an abnormality. And so it turned out. The computed tomography scan of the blood vessels to my kidneys showed a "lesion" in my liver. The test was repeated several weeks later, and when that proved inconclusive, I was sent, after another delay, for a magnetic resonance imaging scan.

When I turned up at the clinic to get the results, I was told (after a 90 minute wait) that the doctors were still unsure about the nature of the lesion: it could be a haemangioma or secondary cancer, or various other things. I would have to come back a week later to hear the verdict of a multidisciplinary team meeting, which was going to look at it.

I was furious. Why had I been made to wait so long just to be told to come back the next week? It was at moments like that when I wanted to throw in the towel and tell the doctors that Ray would just have to wait for a cadaver kidney like everyone else.

When I returned, still seething a week later, I was told it was almost certainly benign. And finally, a couple of weeks later, I was sent a letter saying that I was sufficiently healthy to be a donor. Meanwhile, Ray was also having tests and he was finally given the all clear in July 2007. 


\section{Galloping home}

In contrast to the long drawn out and frustrating saga of the tests, the final stages of the journey were performed at a satisfying gallop. My surgeon gave me a clear account of the risks of the surgery and the potential problems of having only one kidney, and I was warned of the possibility $(5 \%)$ that the kidney could be rejected.

Both Ray and I were then seen by an independent assessor, whose job was to ensure that both of us understood the risks, that no pressure was being put on me, and that I was not being paid. She sent her report to the Human Tissue Authority within 24 hours, and-as it is obliged to do - the authority responded within a few days. The operation went ahead 12 days later.

I cannot pretend that I was not nervous just before the operation. My biggest fear was that something would go wrong with the anaesthetic and I would wake up with some cognitive or physical impairment. As soon as I came round from the operation and found that I could talk and was able to wiggle all my fingers and toes, I was engulfed in a great wave of relief and knew everything was going to be all right.

\section{A satisfying conclusion}

The operation was performed laparoscopically, and my recovery was swift. I was discharged from hospital after three days and was back at work five weeks later.

Ray took rather longer to recover. The donated kidney started working almost immediately, and his creatinine concentrations fell from 420 (high) to about 125 (normal). But it took a while for him to adjust to the antirejection drugs and other drugs that he had to take and for the doctors to find the right doses.

He and Denise have expressed profuse thanks to me for my donation, but I have told them quite genuinely that such thanks are unnecessary. They did not ask me to provide a kidney and they never put the slightest pressure on me to do so. I did it entirely voluntarily and have derived a great deal of satisfaction from it. We all remain good friends. It has not caused any complications to our relationship, and we all feel a strengthened bond from having gone through the operation and recovery period together.

The Royal Free Hospital, where the operation took place, is keen to expand its programme of live donor transplants, because of the shortage of cadaver organs and because the success rates are better than those for cadaver transplants. But I was left wondering whether it had the capacity to do so.

Competing interests: None declared.

Patient (the recipient) consent obtained.

Provenance and peer review: Not commissioned; not externally peer reviewed.

\section{Drug point \\ Topical choline salicylates implicated in Reye's syndrome}

Salicylate use in children was implicated in the development of Reye's syndrome. ${ }^{1}$ After the recommendation in the 1980s that preparations containing aspirin should not be given to children unless specifically indicated, Reye's syndrome has almost disappeared from clinical practice. ${ }^{2}$ The Medicines and Health products Regulatory Agency (MHRA) states that only systemically absorbed acetylsalicylates are associated with Reye's syndrome.

A 20 month old boy (weighing $10 \mathrm{~kg}$ ) presented with a one day history of severe vomiting, lethargy, and photophobia. He had had a viral illness one week earlier and was receiving no medication other than teething gel, one tube each day. He was lethargic, extremely irritable, with a high pitched cry. Investigations revealed raised white cell count $\left(15.2 \times 10^{9} / 1-\right.$ mostly lymphocytes $)$, blood glucose of $2.5 \mathrm{mmol} / \mathrm{l}$ (transient), and normal cerebrospinal fluid. Treatment with ceftriaxone was started, but the patient remained irritable with a normal temperature. Liver function tests performed 24 hours later showed raised transaminases (10 times normal) and a salicylate concentration of $227 \mathrm{mg} / \mathrm{l}$ (therapeutic range $150-200 \mathrm{mg} / \mathrm{l})$. Serum ammonia, coagulation, urine toxicology, and metabolic screens were normal.

The source of salicylate was identified as the teething gel, which contained choline salicylate. After withdrawal of all medication, including teething gel, symptoms settled, and liver transaminases returned to normal within two weeks.
The dose of choline salicylate applied ( $1.31 \mathrm{~g} /$ day), the equivalent of $100 \mathrm{mg} / \mathrm{kg} /$ day of acetylsalicylate, exceeds the recommended dose of teething gel but is similar to the dose of acetylsalicylate used in Kawasaki syndrome. A diagnosis of Reye's syndrome was made after exclusion of metabolic disorders and in light of only mild elevation in salicylate concentration above the therapeutic range.

Only two adverse drug reports were received by the MHRA suggesting an association between Reye's syndrome and choline salicylate: neither provided enough evidence to support a causal relation. This case suggests that topical choline salicylate in teething gels can cause Reye's syndrome.

T K Oman senior house officer, Royal Belfast Hospital for Sick Children, Belfast BT12 6BE and Department of Child Health, Queen's University of Belfast, Belfast

tudorandlucy@gmail.com

M C Stewart senior lecturer, Department of Child Health, Queen's University of Belfast, Belfast

A Burns pharmacist, Pharmacy Department, The Royal Group Hospitals, Belfast

TF Lang principal biochemist, Clinical Biochemistry Department, The Royal Group Hospitals, Belfast

Accepted: 1 October 2007

Competing interests: None declared.

1 Ermias DB, Joseph SB, Robert CH, Ali SK. Reye's syndrome in the United States from 1981 through 1997. N Engl/ Med 1999;340:1377-82.

2 Monto AS. The disappearance of Reye's syndrome-a public health triumph. N EnglJ Med 1999;340:1423-4. 